\title{
Prevent Intravenous Therapy (IV) Contamination by Addition of Magnesium Oxide Nanoparticles to Silicone Rubber
}

\author{
Auda Jabbar Braihi Jaleel Kareem Ahmed Rami Sattar Jabbar \\ Polymer and petrochemical industries, college of Engineering materials, Babylon University, \\ Iraq.
}

auda_1964@yahoo.com jaleel_karim@yahoo.com rami.st.94@gmail.com

\begin{tabular}{|l|l|l|}
\hline Submission date:- 27/1/2019 & Acceptance date:- 13/3/2019 & Publication date:- 8/4/2019 \\
\hline
\end{tabular}

\begin{abstract}
Antibacterial material nanocomposites are prepared to manufacture intravenous therapy (IV). These composites prepared by adding Magnesium oxide nano powder $(\mathrm{MgO} N$ Ps) with a different percent $(3,6$, and $9 \mathrm{wt} \%$ ) to Silicone rubber (SR). The activity of this antibacterial material was inspected against $S$. aureus and E.coli microorganisms by using Agar Well Diffusion method.

Results showed that the addition of MgO NPs to SiR causes the following enhancement the antibacterial activity against E.coli and S.aureus by $7.1 \%$ and $27.1 \%$ respectively, increasing tensile strength by $65.5 \%$, increasing the hardness by $11.25 \%$, increasing the wear resistance by $84.5 \%$, increasing surface bearing index (Sbi) by $80.5 \%$, increasing in core fluid retention (Sci) by $8.5 \%$, decreasing surface roughness (Sa) by $65 \%$, decreasing core roughness depth (Sk) by $67 \%$ and enhancement the wettability by decreases contact angle to minimum value.
\end{abstract}

Keywords: Antibacterial polymer, Silicone rubber, Magnesium Oxide, Inhibition zone.

\subsection{Introduction}

In recent decades, nanocomposites have been taken into consideration because of their excellent properties and applications. Through all nanocomposites, antimicrobial polymer-metallic nanocomposites have outstanding antimicrobial properties and prospective applications[1].

Recently, many hospital tools are made of plastics. Plastics are strong and able to resist repeated sterilization, server temperatures and chemical environment. Polymeric materials play a substantial role in the transmission of infection because they allow the growth of fungi and bacteria[2] .

The probability of hospitalized patients dies from a hospital-acquired infection is 2.4 times more likely than they are from a road accident when compared to the crash fatality data [3].

Contamination by microorganisms is the main factor in a variety of areas, such as medical devices, healthcare products, hospital, food storage, food packaging, and dental equipment etc. So to overcome this problem different types of plastic material are sterilized and antisepsis by a different methods such as dry/wet heating or ionic radiation. However, microorganisms can contaminate these polymers when they exposed to the atmosphere. There is an immediate need for new material with antibacterial activity [4].

Cleaning and disinfection in operating rooms are rarely optimal and do not always reduce or eliminate contamination on environmental surfaces

The incidence of diseases, the spread of microorganisms and inefficient sterilization methods either by affecting on the item or being temporary, was the main reasons for needing to new and effective prevention method [5].

Antibiotic-resistant bacteria, disease transmission, spread of infections and biocides formations are the main challenge of modern medical technology. To overcome these problems, antimicrobial polymers are used. Antimicrobial polymeric materials can be applied in drug delivery, wound healing or dressing,

JOURNAL OF UNIVERSITY OF BABYLON FOR ENGINEERING SCIENCES by University of Babylon is licensed under a Creative Commons Attribution 4.0 International License. 
sutures, and dental application [6]. There are many methods used to prevent contamination, such as antibacterial agent [7].

For example, a human has used magnesium oxide $(\mathrm{MgO})$ as an antibacterial agent. $\mathrm{MgO}$ NPs are safe inorganic materials to human beings have antibacterial action against many microorganisms. The main advantages of using inorganic antimicrobial agents such as $(\mathrm{MgO}, \mathrm{ZnO}, \mathrm{CaO})$, compared to organic antibacterial agents, are the improved stability under difficult processing conditions [8]. MgO NPs exhibits unique mechanical, magnetic, thermal, optical electronic and chemical properties, due to its characteristic structures [9]. Therefore, $\mathrm{MgO}$ NPs has been widely used in catalysis, refractory materials industries based on its versatile properties, medicine, and toxic waste remediation [10].

$\mathrm{MgO}$ NPs has good antibacterial activity against many microorganisms such as E.coli and S.aureus and the inhibition zone increases with increase Mgo NPs concentration [11, 12].

\subsection{Aim of Study} Properties

Preparing antibacterial material for Intravenous therapy (IV) tubing with good mechanical

\section{2- Experimental part}

\subsection{Materials:}

Silicone rubber (SR) was purchased from Shenzhen Hong Ye Jie Technology Co., Ltd, China with the properties maintained in table (1) and the Magnesium oxide nanopowders (MgO NPs) was purchased from Nanjing High Technology Nano Material Co., Ltd., Nanjing, Jiangsu, China with the properties in table (2).

Table (1) Properties of Silicone Rubber

\begin{tabular}{|c|c|}
\hline Property & Data \\
\hline Density & $1.05 \mathrm{~g} / \mathrm{cm}^{3}$ \\
\hline Vulcanization time at RT & $3-4 \mathrm{~h}$ \\
\hline Tensile strength & $\geq 10 \mathrm{MPa}$ \\
\hline Tear strength & $26 \pm 2 \mathrm{KN} / \mathrm{m}$ \\
\hline
\end{tabular}

Table (2) Properties of magnesium oxide nanoparticles

\begin{tabular}{|c|c|}
\hline Property & Data \\
\hline Purity & $99.9 \%$ \\
\hline size & $30-40 \mathrm{~nm}$ \\
\hline Crystal & White \\
\hline
\end{tabular}

\subsection{Procedure}

Casting method is used to prepare the sheet of $\mathrm{SR} / \mathrm{MgO}$ NPs by mixing $10 \mathrm{~g}$ of SR mixed with $(3,6$, and $9 \mathrm{wt} \%) \mathrm{MgO}$ NPs using bath sonication for $1 \mathrm{~h}$ at $50^{\circ} \mathrm{C}$, and then the hardener is added in ratio (4:100) to the mixture and mixed for 5 min by a mechanical stirrer and pour in a suitable mold.

\subsection{Characterizations}

The Agar Well Diffusion method is used to measure the antibacterial performance for SiR/MgO nanocomposites. Universal Testing Machine type (WDW/5E) used to locate the tensile strength according to ASTM D-638-02A. Hardness studied according to ASTM D-1706, while wear test measured according to ASTM G99. Contact Angle Meter used to evaluate the Wettability.

The surface morphologies were made by AFM (AA3000) and Scanning Electron Microscope (FESEM) model (SUPRA 55-VP-48-06). 


\section{3- Results and Discussion}

\subsection{Antibacterial activity}

Antibacterial activity of SR/MgO NPs composites was determined by measurement the diameter of inhibition zone $(\mathrm{mm})$ after $24 \mathrm{~h}$, In comparison with a control sample against Staphylococcus aureus (S. aureus) and Escherichia coli (E.coli) microorganisms, which are gram-positive and gram-negative respectively.

The result showed that the maximum inhibition zone (IZ) at concentration of $\mathrm{MgO}(9 \mathrm{wt} \%)$ against bacteria E.coli and S.aureus are $(15,14.5 \mathrm{~mm})$ respectively and a minimum of IZ at concentration of $\mathrm{MgO}$ NPs (3 wt \%) against bacteria E.coli and S.aureus are $(14,11.5 \mathrm{~mm}$ respectively) as shown in Figure (1). Seemingly from this figure that $\mathrm{MgO}$ nanoparticle causes a significant increase in action against both the used microorganisms. This is because that MgO NPs aggressive hydroxide (alkaline) with pH> $7 \mathrm{higher}$ than $\mathrm{pH}$ of bacteria.

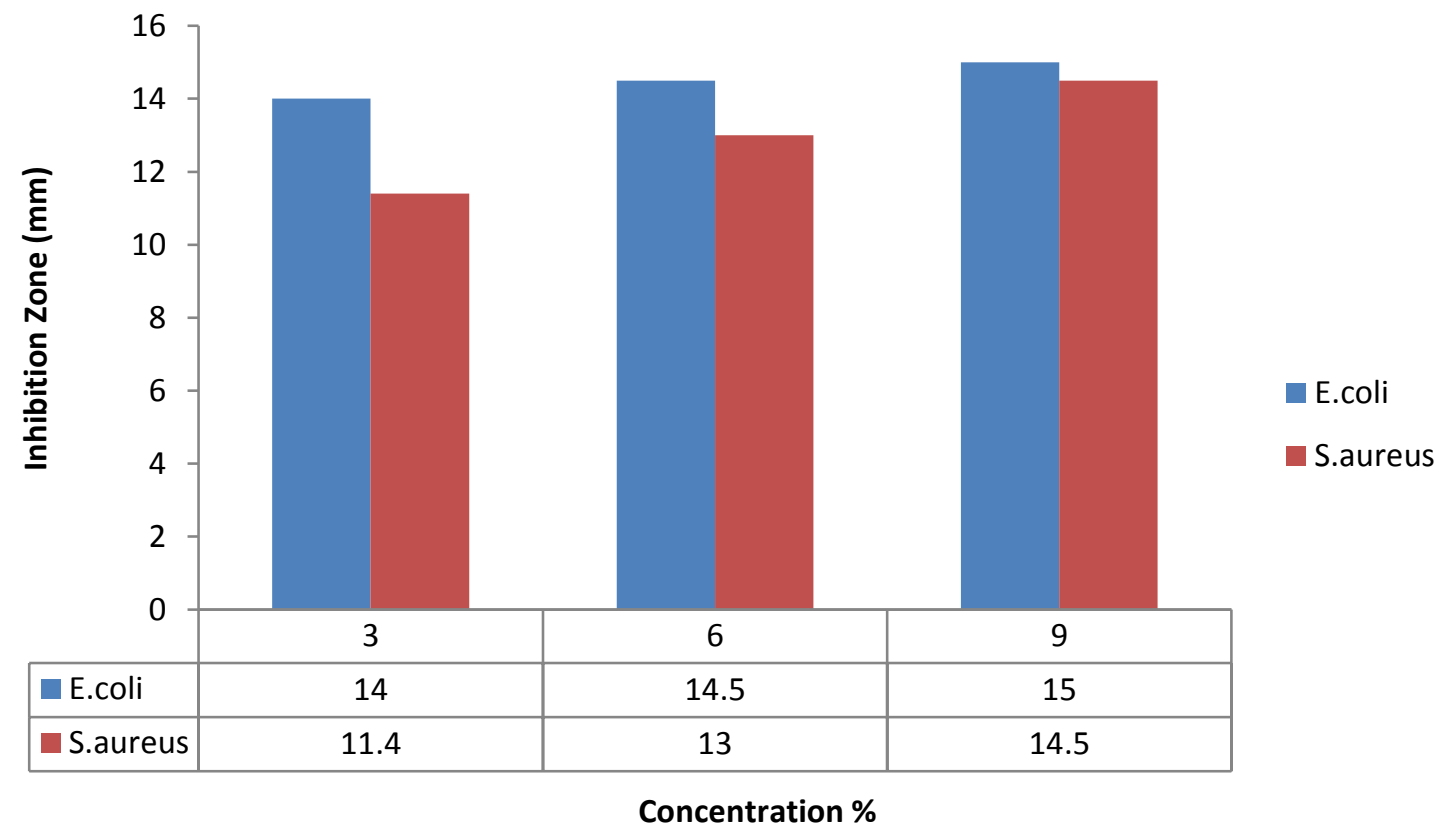

Figure (1): Antibacterial activity for SR/MgO nanocomposite

The inhibition efficiency (IE) was calculated according to the following equation.

$$
I E=\frac{(I Z) \text { at high concentration }-(I Z) \text { at low concentration }}{(\text { IZ)one at low concentration }} * 100
$$

The results showed that the inhibition efficiency (IE) of 9wt\% MgO NPs against E.coli and S.aureus increased by $7.1 \%$ and $27.1 \%$ respectively compared with $3 \mathrm{wt} \%$ P-Ag NPs.

\subsection{Mechanical properties}

Figures (2) and (3) show the effect of Mgo NPs concentrations on tensile and hardness (shore A) performance. Note that the pure SR sheet has a lower tensile strength and hardness than SR/ MgO NPs.

At a concentration of $9 \mathrm{wt} \%$, the composite material has a maximum tensile strength (18.2 $\mathrm{MPa})$ and highest hardness with (33.375) compared with pure SR, which means that, increasing the concentration of 
$\mathrm{MgO}$ NPs led's to increase in mechanical properties of SR/MgO NPs due to the MgO NPs are heavy metals have good mechanical properties.

On the other hand, abrasive wear resistance increases with increasing $\mathrm{MgO}$ NPs as shown in Figure (4). The result proved that the weight loss of SR/MgO NPs sheet minimized to the smallest value $(1.27 \%)$ with increase concentration of MgO NPs due to the previous reason.

\subsection{Surface Wettability}

The contact angle method used to evaluate the effect of addition antibacterial agent on the wettability of resultant composites. The results showed the addition of antibacterial agent (MgO NPs) can decrease the contact angle due to the ability of $\mathrm{MgO}$ to absorb water and changed to aggressive alkaline hydroxide and killing all microorganisms as shown in Figure (5).

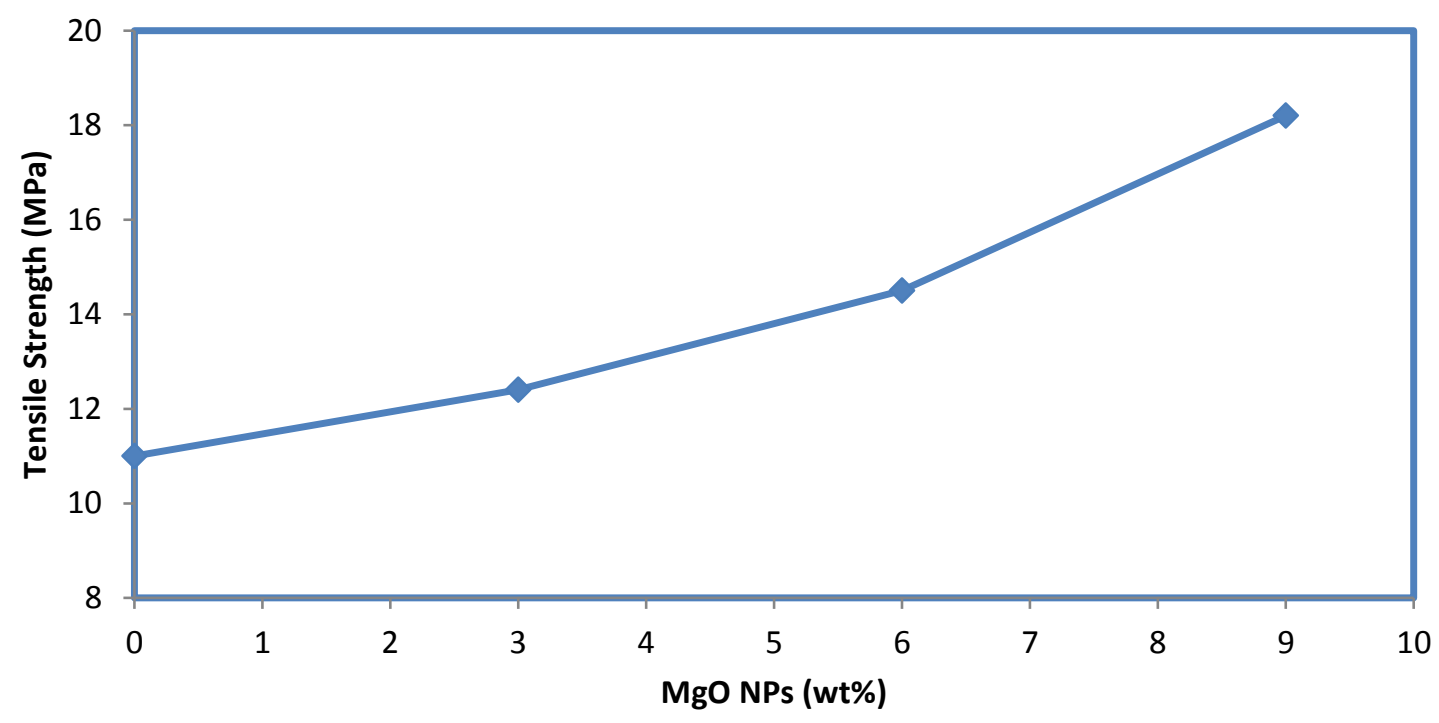

Figure (2): Tensile strength as a function of MgO NPs concentration

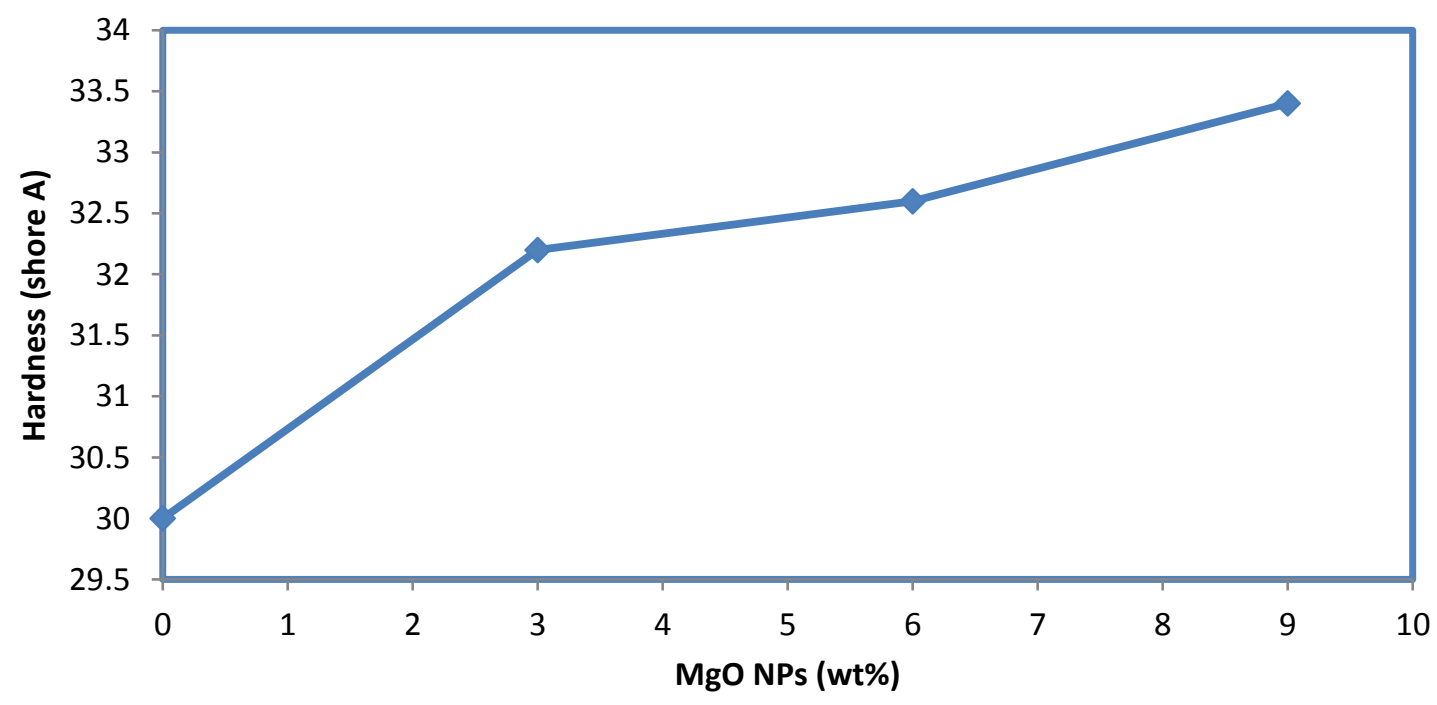

Figure (3): Hardness as a function of MgO NPs concentration 
Journal of University of Babylon for Engineering Sciences, Vol. (27), No. (1): 2019.

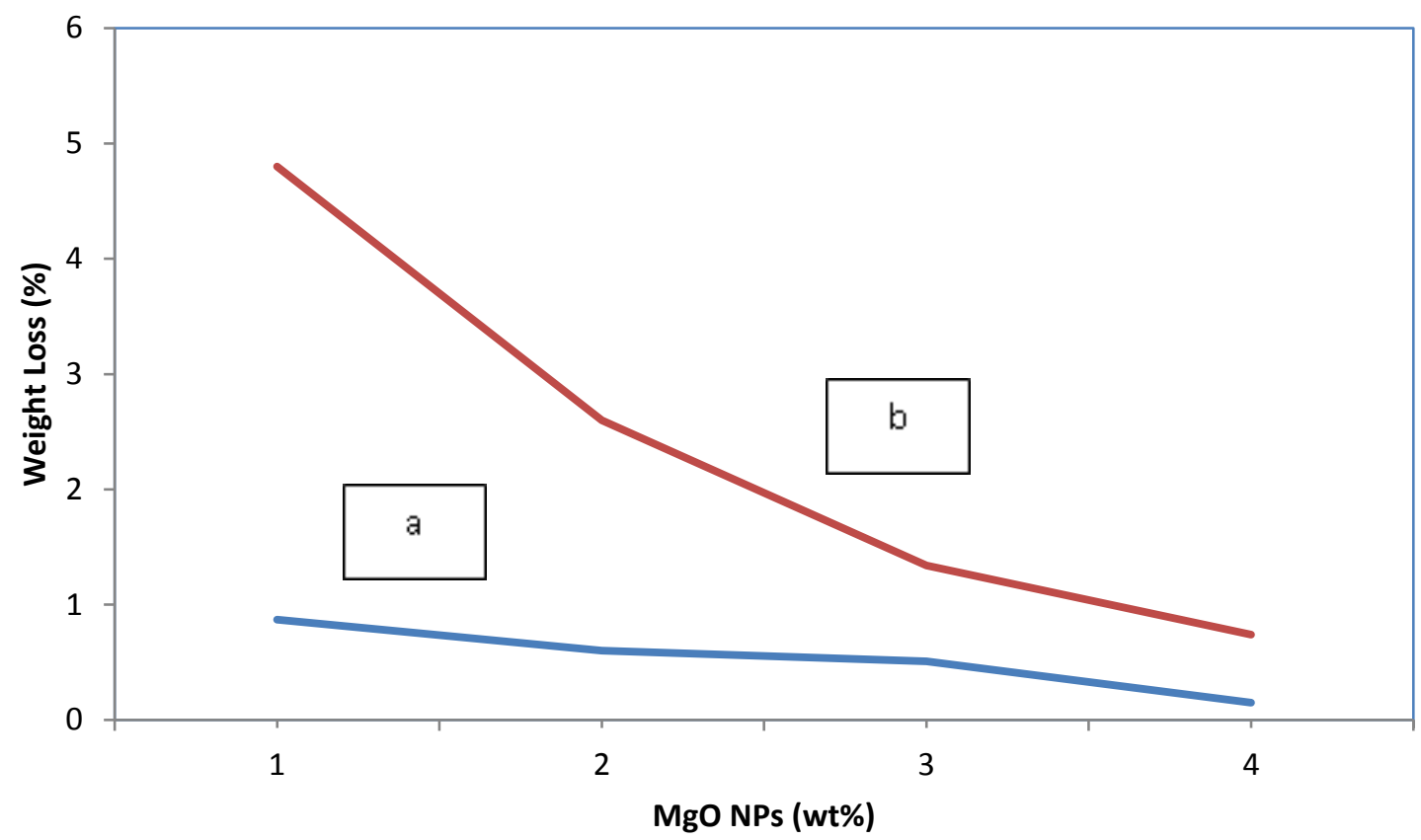

Figure (4): Weight loss as a function of MgO NPs concentration by wear at

(a) $15 \mathrm{~N} \&$ (b) $30 \mathrm{~N}$

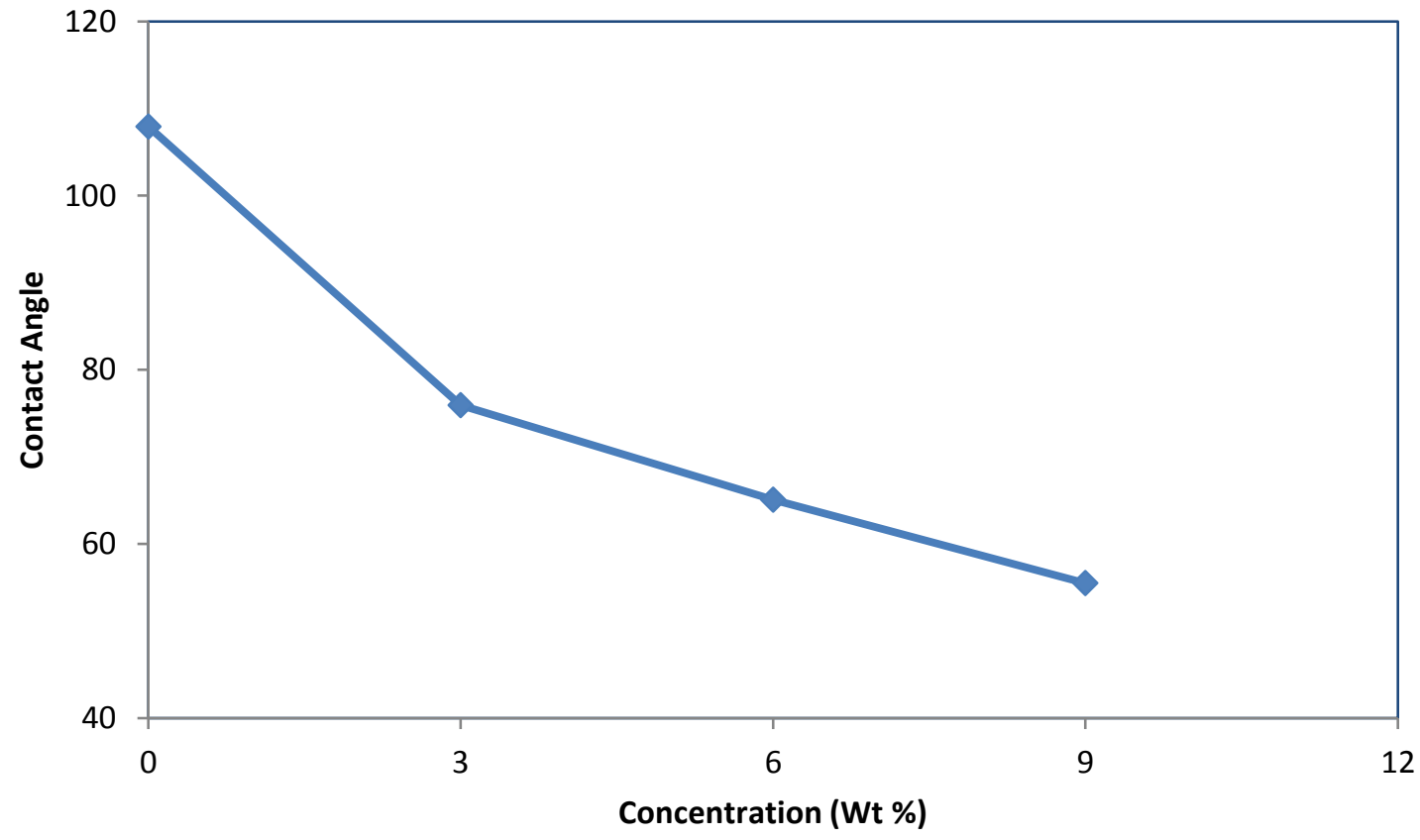

Figure (5): Wettability for SR/MgO NPs 


\subsection{Morphology parameters}

AFM used to study morphological properties. The results showed that the surface roughness (Sa) for $\mathrm{SR} / \mathrm{MgO}$ NPs composites decreased with the antibacterial agents addition, which means that the surface becomes smoother and with fewer cavities and voids.

As shown in figure (6), addition of antibacterial agent $(\mathrm{MgO})$ to the $(\mathrm{SR})$ can reduce the surface roughness $(\mathrm{Sa})$ by $65 \%$, decrease core roughness depth $(\mathrm{Sk})$ by $67 \%$, increase surface bearing index (Sbi) by $80.5 \%$, increasing in core fluid retention (Sci) by $8.5 \%$ due to the $(\mathrm{MgO})$ is aggressive alkaline hydroxide with hydrophilic surface and enhance the wettability by decreases contact angle with minimum value. These finding coincide with the 3D images from the AFM test (figure 7), where the area of the cavities decreased with increasing MgO NPs concentration.

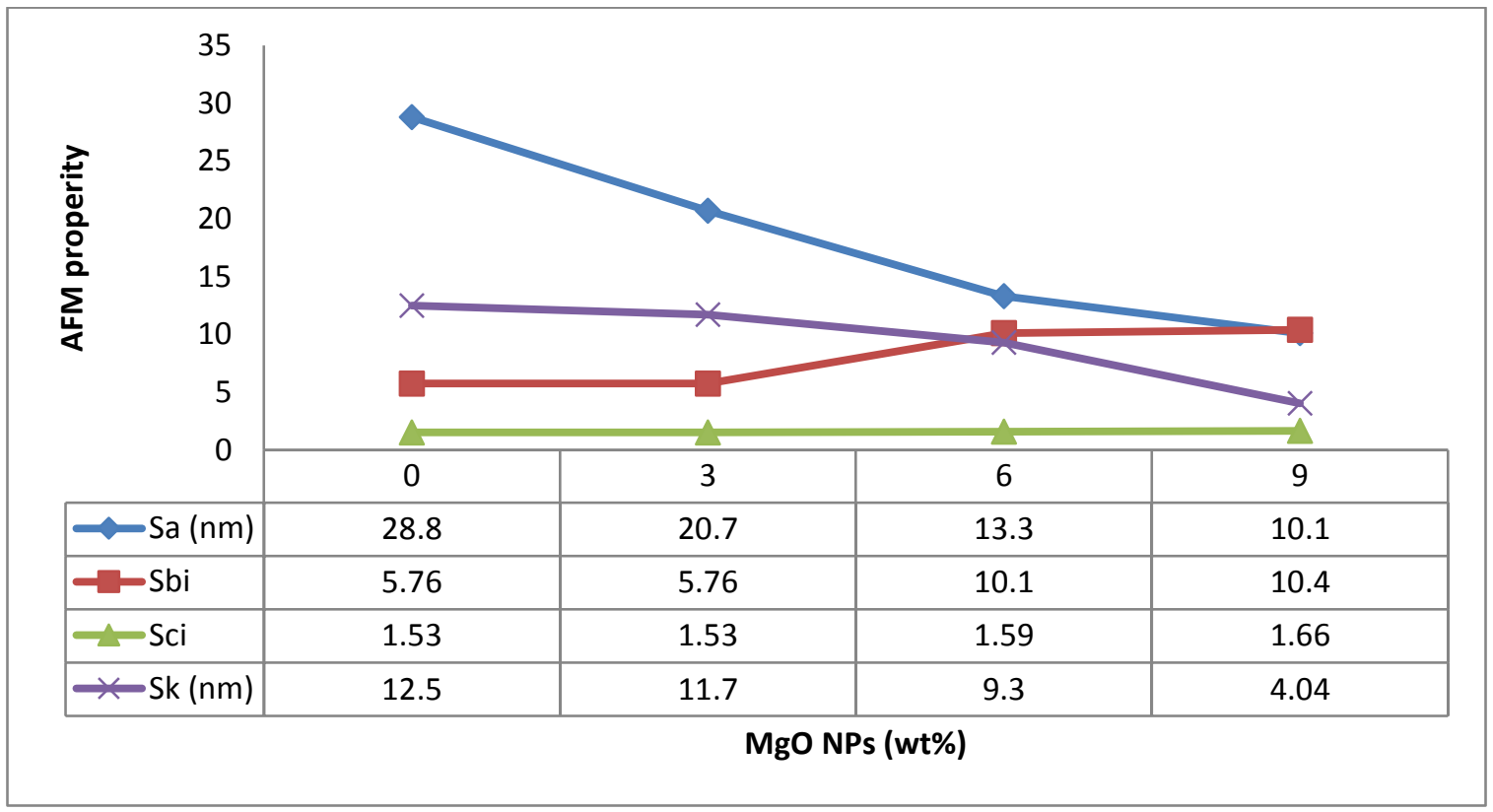

Figure (6): Sa, Sbi, Sci and Sk AFM properties of SR/MgO NPs

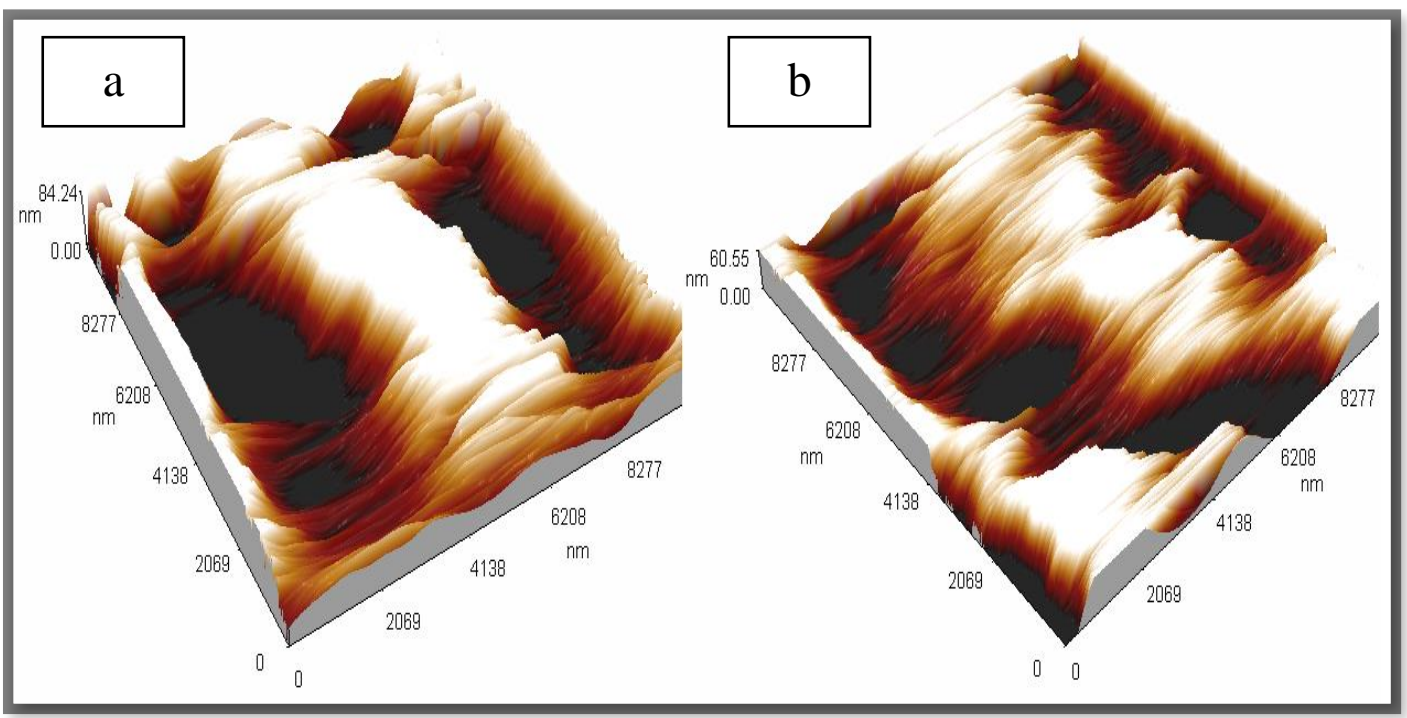

Figure (7): 3D AFM images of (a) SR (b) SR/Mgo NPs (9wt \%) 


\subsection{Scanning Electron Microscope (SEM) Test}

SEM image for pure SR and SR/MgO NPs (figures 8 and 9 respectively) shows that the antibacterial agents were evenly distributed in the SR. Also, number of cavities and voids decreased so that the surface switch backs decreased and the surface become smoother. The good distribution of MgO NPs on the surface of material enhances the ability to killing bacteria due to MgO NPs are aggressive alkaline hydroxide. That mean the surface will be impervious against attacked of microorganisms.

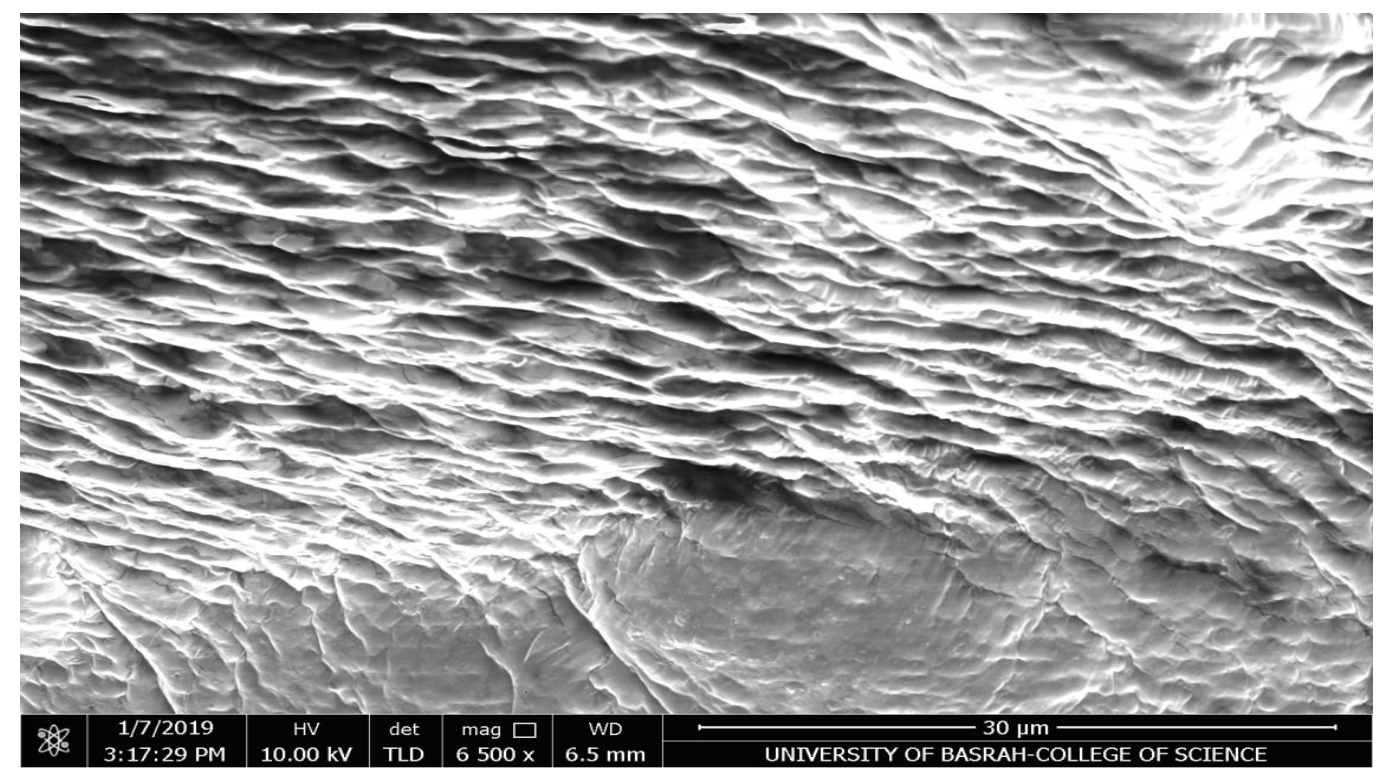

Figure (8): SEM image of pure SR

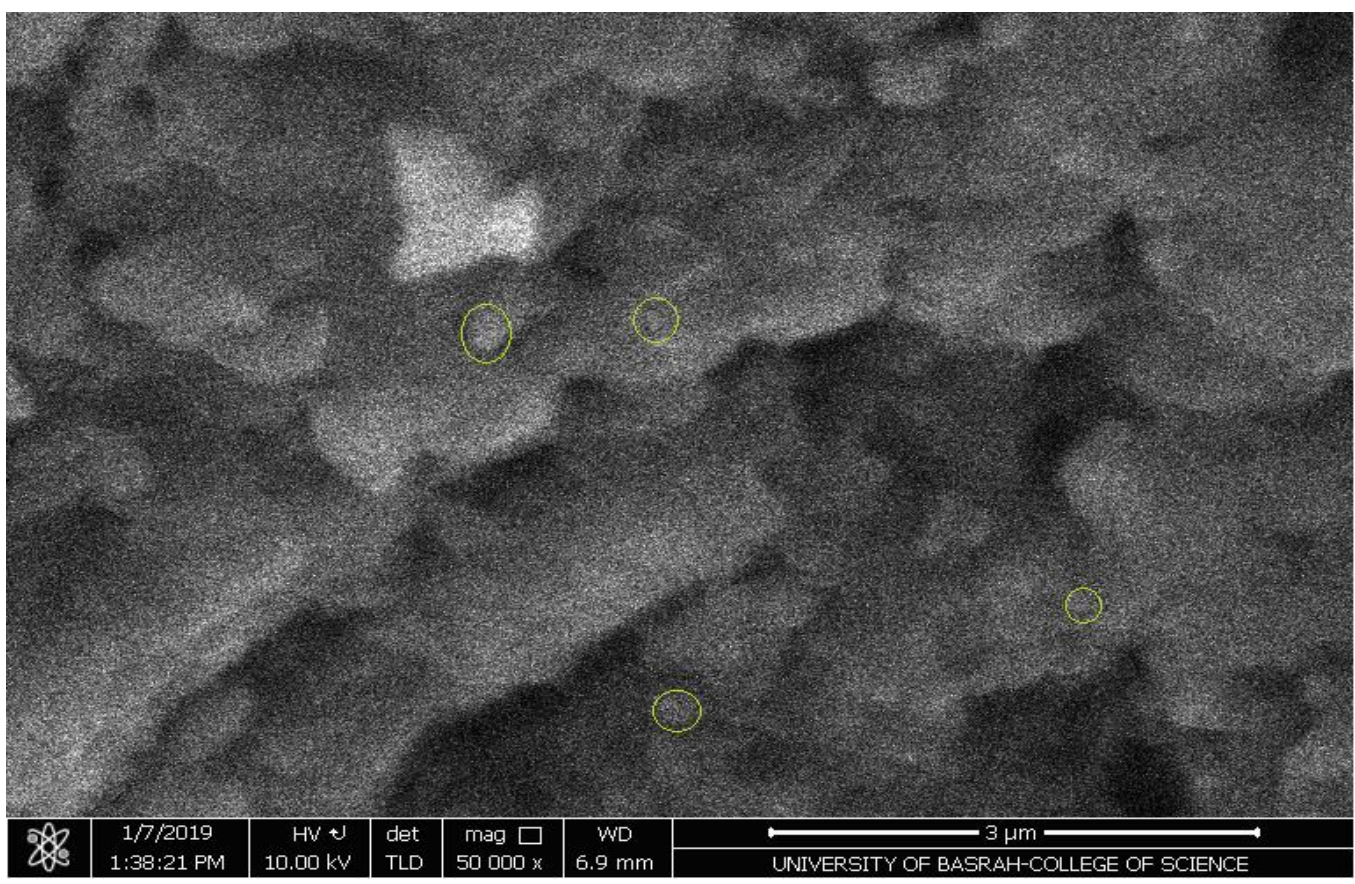

Figure (9): SEM image of composite material SR/MgO NPs at concentration of 9wt \% 


\section{Conclusions}

1. SR/MgO NPs have antibacterial ability against both E.coli and S. aureus microorganisms.

2. Mgo is suitable for IV tubes.

3. For SR/MgO NPs the antibacterial activity, tensile strength, hardness, wear resistance, surface bearing ability (Sbi) and core fluid retention (Sci) increased as MgO NPs increased.

4. $\mathrm{MgO}$ NPs are aggressive hydroxide with $\mathrm{pH}>7$.

5. SEM images show increasing in surface smoothness and good disperation of particles in polymer matrix.

6. The optimum concentration of $\mathrm{MgO}$ NPs is $9 \mathrm{wt} \%$ against both $S$. aureus and E.coli microorganisms.

\section{CONFLICT OF INTERESTS.}

- There are no conflicts of interest.

\section{References}

[1] S. M. Li, N. Jia, M. G. Ma, Z. Zhang, Q. H. Liu, and R. C. Sun, "Cellulose-silver nanocomposites: Microwave-assisted synthesis, characterization, their thermal stability, and antimicrobial property," Carbohydr. Polymer, 2011.

[2] J. A. Avila-Alfaro et al., "Ultrasound Irradiation Coating of Silver Nanoparticle on ABS Sheet Surface," J. Inorg. Organomet. Polymer. Mater. Vol. 23, No. 3, pp. 673-683, 2013

[3] F. Siedenbiedel and J. C. Tiller, "Antimicrobial polymers in solution and on surfaces: Overview and functional principles," Polymers (Basel). Vol. 4, No. 1, pp. 46-71, 2012

[4] A. K. A .Wadi "Preparation and Characterization of Polymeric Composites as Antibacterial Surfaces for Medical Applications," M.S.c thesis, Dept. Polymer and petrochemical industries, University of Babylon, Iraq, 2017.

[5] S. Yezli, F. Barbut and J.A. Otter "Surface contamination in operating rooms: a risk for transmission of pathogens". Surgical infections, Vol. 15, No. 6, pp. 694-699, 2014.

[6] M. Álvarez-Paino, A. Muñoz-Bonilla and M. Fernández-García "Antimicrobial polymers in the nanoworld, Nanomaterials" Vol. 7, No. 2, pp. 48, 2017.

[7] F. Siedenbiedel and J.C. Tiller "Antimicrobial polymers in solution and on surfaces: overview and functional principles, Polymers".Vol. 4, No. 1, pp. 46-71, 2012.

[8] Z. X. Tang and B. F. Lv "MgO nanoparticles as antibacterial agent: preparation and activity," Brazilian Journal of Chemical Engineering., Vol. 31, No. 3, pp. 591-601, 2014.

[9] Z. Camtakan, S. Erenturk and S. Yusan "Magnesium oxide nanoparticles: preparation, characterization, and uranium sorption properties," Environmental Progress \& Sustainable Energy., Vol. 31, No. 4, pp. 536-543, 2012.

[10] I. R. Agool, K. J. Kadhim and A. Hashim "Synthesis of (PVA-PEG-PVP-MgO) nanobiomaterials and their application," Advances in Environmental Biology., Vol. 9, No. 27, pp. 101-106, 2015.

[11] J. K. Ahmed, A. J. Braihi and D. A. Kadham "Poly (Vinyl-alcohol)-Iodine Bio-composites and Their Applications," .International Journal of Pharmaceutical and Phytopharmacological Research (eIJPPR), Vol.7, Issue 5, pp. 1-8, 2017.

[12] A. J. Braihi, J. K. Ahmed and D. A. Kadham, "Preparing Medical (Poly Vinyl Alcohol-Iodine) As A Pressure Sensor and Investigating its Physical Properties," .International Journal of Pharmaceutical and Psychopharmacological (eIJPPR), Vol.7, Issue 5, pp.1-8, 2017. 
منع تلوث العلاج الداخل عن طريق الانابيب الوريدية (IV) بإضافة جسيمات أكسيد المغنيسيوم النانوية لمطاط السيليكون

\author{
عودة جبار بريهي جليل كريم احمدرامي ستار جبار \\ قسم البوليمرات والصناعات بتروكبياوية، كلية هندسة الدواد، جامعة بابل، العراق.
}

rami.st.94@gmail.com $\quad$ jaleel karim@yahoo.com auda 1964@yahoo.com

الخلاصة

المواد النانوية المتر اكبة المضادة للبكتيريا تم تحضيرها لاستخدامها كأنايبب لادخال العلاج عن طريق الوريد (IV). حيث

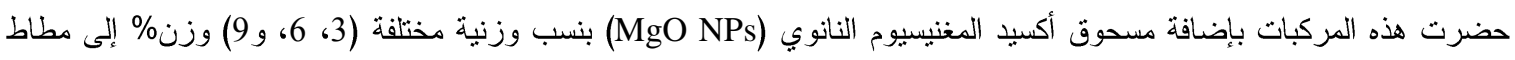

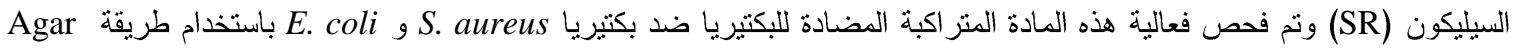
.Well Diffusion

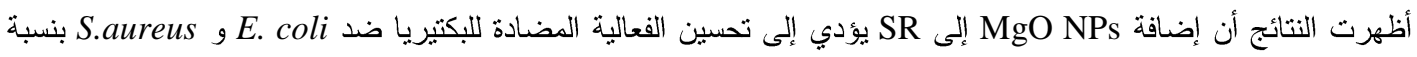
7.1 ٪ و 27.1 ٪ على التو الي ، وزيادة قوة الثند بنسبة 65.5 ٪ ، وزيادة الصلابة بنسبة 11.25 ٪ ، وزيادة مقاومة البلى بنسبة 84.5

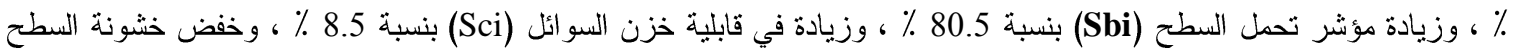
(Sa) بنسبة 65 ٪ ، وخفض عمق الخشونة الأساسية (SK) بنسبة 67 ٪ و تحسين قابلية الترطيب للسطوح من خلال تقليل زاوية التلامس إلى اقل قيمة. الكلمات الدالة: - البوليمر ات المضادة للبكتيريا، مطاط السيليكون، أكسيد المغنيسيوم، منطقة التثبيط. 